\title{
Indirect cholinergic activation slows down pancreatic cancer growth and tumor- associated inflammation
}

Paulo L. Pfitzinger ${ }^{1 \dagger}$, Laura Fangmann ${ }^{1 \dagger}$, Kun Wang $^{2}$, Elke Demir ${ }^{1}$, Engin Gürlevik ${ }^{3}$, Bettina Fleischmann-Mundt ${ }^{3}$, Jennifer Brooks ${ }^{3}$, Jan G. D'Haese ${ }^{4}$, Steffen Teller ${ }^{1}$, Andreas Hecker ${ }^{5}$, Moritz Jesinghaus ${ }^{6}$, Carsten Jäger ${ }^{1}$, Lei Ren ${ }^{1,7}$, Rouzanna Istvanffy' ${ }^{1}$, Florian Kühnel ${ }^{3}$, Helmut Friess ${ }^{1,8,9}$, Güralp Onur Ceyhan ${ }^{10}$ and Ihsan Ekin Demir ${ }^{1,8,9,10^{*}}$ (1)

\begin{abstract}
Background: Nerve-cancer interactions are increasingly recognized to be of paramount importance for the emergence and progression of pancreatic cancer (PCa). Here, we investigated the role of indirect cholinergic activation on PCa progression through inhibition of acetylcholinesterase (AChE) via clinically available AChEinhibitors, i.e. physostigmine and pyridostigmine.
\end{abstract}

Methods: We applied immunohistochemistry, immunoblotting, MTT-viability, invasion, flow-cytometric-cell-cycleassays, phospho-kinase arrays, multiplex ELISA and xenografted mice to assess the impact of AChE inhibition on PCa cell growth and invasiveness, and tumor-associated inflammation. Survival analyses were performed in a novel genetically-induced, surgically-resectable mouse model of PCa under adjuvant treatment with gemcitabine+/ -physostigmine/pyridostigmine ( $n=30$ mice). Human PCa specimens $(n=39)$ were analyzed for the impact of cancer AChE expression on tumor stage and survival.

Results: We discovered a strong expression of AChE in cancer cells of human PCa specimens. Inhibition of this cancer-cell-intrinsic AChE via pyridostigmine and physostigmine, or administration of acetylcholine (ACh), diminished PCa cell viability and invasion in vitro and in vivo via suppression of pERK signaling, and reduced tumorassociated macrophage (TAM) infiltration and serum pro-inflammatory cytokine levels. In the novel geneticallyinduced, surgically-resectable PCa mouse model, adjuvant co-therapy with AChE blockers had no impact on survival. Accordingly, survival of resected PCa patients did not differ based on tumor AChE expression levels. Patients with higher-stage PCa also exhibited loss of the ACh-synthesizing enzyme, choline-acetyltransferase (ChAT), in their nerves.

Conclusion: For future clinical trials of $\mathrm{PCa}$, direct cholinergic stimulation of the muscarinic signaling, rather than indirect activation via AChE blockade, may be a more effective strategy.

Keywords: Cholinergic, Acetylcholinesterase, Pancreatic cancer, Parasympathomimetics, Electroporation

\footnotetext{
*Correspondence: ekin.demir@tum.de

${ }^{\dagger}$ Paulo L. Pfitzinger and Laura Fangmann contributed equally to this work. 'Department of Surgery, Klinikum rechts der Isar, Technical University of Munich, School of Medicine, Ismaninger Str. 22, 81675 Munich, Germany ${ }^{8}$ German Cancer Consortium (DKTK), Partner Site Munich, Munich, Germany Full list of author information is available at the end of the article
} 


\section{Background}

The autonomous nervous system has been recently discovered to impact on cancer growth and progression in several solid and hematological cancers [1]. In pancreatic cancer $(\mathrm{PCa})$, surgical denervation via vagotomy or pharmacological suppression of the cholinergic signaling were shown to exert a cancer-promoting effect $[2,3]$. In genetically induced LSL-Kras ${ }^{+/ G 12 D}$;Pdx1-Cre (KC) mouse model of $\mathrm{PCa}$, subdiaphragmatic vagotomy led to accelerated cancer growth, and treatment with direct muscarinic agonists restored normal KC phenotype [3]. Here, cholinergic signaling was shown to suppress tumorigenesis and cancer stemness via muscarinic type 1 receptor $\left(M_{1} R\right)$ signaling [3].

However, activation of muscarinic receptors by its main direct agonist, i.e. acetylcholine (ACh), is a process that is not confined to the autonomous nervous system. In fact, non-neuronal cholinergic signaling is highly common in most cell types and has been shown to regulate basic cell functions, such as proliferation, differentiation and apoptosis [4-6]. In this context, the role of non-neuronal acetylcholine as a local signaling molecule is often disregarded $[7,8]$. Together with its corresponding degrading and synthesizing enzymes (acetylcholine esterase/AChE and choline acetyltransferase/ChAT), it is expressed in many eukaryotic cell types and even in plants and primitive uni- and multicellular organisms with no autonomous nervous system [8]. Depending on the muscarinic receptor subtype $\left(M_{1} R-M_{5} R\right)$ to which ACh binds, muscarinic signaling can result in diverse cellular functions. The most potent and relevant ACh receptors that mediate cell proliferation and cell growth are muscarinic receptor type $1\left(\mathrm{M}_{1} \mathrm{R}\right)$ and type $3\left(\mathrm{M}_{3} \mathrm{R}\right)$; both widely expressed in most human tissues and especially in gastrointestinal tissues [5, 9]. Local availability of ACh for autocrine and paracrine stimulation of muscarinic receptors regulates not only various physiological cell functions, but has also been shown to critically contribute to tumorigenesis [4]. For instance, in colon, breast and liver cancer, muscarinic receptor activation increased cancer cell proliferation and contributed to cancer progression [10-12]. This effect was mainly attributed to $\mathrm{M}_{3} \mathrm{R}$ signaling [13]. Interestingly, in PCa, $M_{1} R$ signaling resulted in reduced tumor growth [3]. This effect was mainly attributed to neuronal cholinergic input, e.g. from the vagus nerve [3]. However, in the $\mathrm{PCa}$ microenvironment, there are though several other non-neuronal sources of acetylcholine, such as cancerassociated fibroblasts and pancreatic stellate cells (PSCs), which are thought to influence pancreatic exocrine function via ACh secretion [14].

In this study, we demonstrate that PCa cell growth can also be decelerated by non-neuronal, indirect cholinergic signaling. This observation suggests that cancer cells, especially pancreatic cancer cells (PCCs), may be largely independent of the autonomous nervous system in their reaction to acetylcholine availability in the tumor microenvironment. Indeed, we demonstrate that human PCCs express high amounts of $\mathrm{AChE}$ and that inhibition of non-neuronal AChE suppressed PCC viability and invasion in vitro and in vivo. Notably, this effect was induced without surgical vagotomy, but only through nonneuronal, tumor cell intrinsic $\mathrm{AChE}$ inhibition. However, survival in a novel genetic, R0-resectable $\mathrm{PCa}$ mouse model was not influenced by AChE inhibition in the adjuvant setting. Accordingly the survival of resected $\mathrm{PCa}$ patients did not differ based on tumor AChE expression levels. These data imply that direct cholinergic stimulation, rather than indirect activation via AChE blockade, may be a more effective therapeutic strategy in PCa.

\section{Methods \\ Cell culture}

The human pancreatic cancer cell lines Panc-1 and SU86.86, the colon carcinoma cell lines SW620 and DLD-1, and the glioblastoma cell line LN229 were purchased from the American Type Culture Collection (ATCC). The T3M-4 cell line was a kind gift by Dr. R. Metzgar (Durham, NC, USA). Cells were kept and cultured in RPMI-1640 supplemented with $10 \%$ fetal calf serum (FCS), $100 \mathrm{U} / \mathrm{ml}$ penicillin and $100 \mu \mathrm{g} / \mathrm{ml}$ streptomycin (Gibco, Invitrogen, Karlsruhe, Germany) in a 5\% $\mathrm{CO}_{2}$ humidified atmosphere at $37^{\circ} \mathrm{C}$.

\section{Matrigel invasion assay}

Five thousand PCCs (SU.86.86) were placed into each chemotaxis chamber insert of a 24-well plate (BD Falcon $^{\circ} 8 \mu \mathrm{m}$, Heidelberg, Germany) and incubated overnight. After $22 \mathrm{~h}$, the inserts were removed, cleaned of non-migrating cells, fixed in $4 \%$ paraformaldehyde, and stained with Vybrant CFDA SE Cell Tracker Kit (Life Technologies, Darmstadt, Germany), and scanned via an automated digital epifluorescence microscope (Keyence BioRevo BZ-9000, Neu-Isenburg, Germany). The number of stained (migrated) cells was counted via ImageJ (version 1.44p, NIH, USA).

\section{Heterotypic xenograft model}

Athymic nude mice (NMRI-Foxn $1^{\mathrm{nu} / \mathrm{nu}}$ ) of 4-5 weeks of age and weighing 15-20 g were kept under standard conditions in sterile cages and given food and water ad libitum. Mice were injected subcutaneously (s.c.) in their neck and dorsum with $4 \times 10^{5}$ cells $(5000$ cells $/ \mu$ l) of the PCa cell line T3M-4, and the animals were divided into two groups for the subsequent treatment: Group I was classified as the "prophylactic" group and treated starting with the day of tumor cell inoculation. Group II were not treated until the 1st week after tumor inoculation to 
allow the tumor to reach a palpable size. Mice were treated with subcutaneous injections of the AChE inhibitors physostigmine or pyridostigmine as indirect parasympathomimetic agents. Physostigmine, which can cross the blood-brain-barrier (BBB), was administered at $0.1 \times \mathrm{LD}_{50}$ and $0.3 \times \mathrm{LD}_{50}$, and Pyridostigmine, which cannot cross the $\mathrm{BBB}$, at $0.2 \times \mathrm{LD}_{50}$ and $0.4 \times \mathrm{LD}_{50}$. Solvent (saline) was injected to the control group. The animals received treatment 5 times a week for a period of 4 and 3 weeks for group I and II respectively. Animals were sacrificed by neck dislocation, and tumor diameter $(\mathrm{mm})$ and local invasive spread (visible cell spread into neighbouring organs) of cancer cells were assessed.

\section{R0-resectable, electroporation induced transgenic mouse model of unilocular PCa}

Current oncogenic Kras-based mouse models of PCa develop multilocular tumors due to constitutive activation of the oncogene in the embryonic phase or due to its inducible activation in the adult age. This modality is not in harmony with human disease, which typically manifests as a single, i.e. unilocular, cancer in the pancreas. To address this discrepancy, Gürlevik et al. recently developed an R0resectable, electroporation-induced genetic mouse model of unilocular $\mathrm{PCa}$, which is induced upon injection and electroporation of plasmids containing the Sleeping Beauty (SB) transposase SB13, a Kras-G12V encoding transposon, and the Cre recombinase into the pancreatic tail of p53floxed mice $\left(p 53^{f l / f l}\right)$ [15]. Details on the plasmid constructs and the electroporation parameters have been described in the original publication [15]. Upon activation of the Cre recombinase, tumor formation was initiated in a local fashion (the "Pfl" model), and 3 weeks after electroporation, the mice developed a unilocular tumor of the pancreatic tail that is amenable to surgical resection (Fig. 5a-b). The model allows real-life-like performance of neoadjuvant and adjuvant therapy trials with these mice, which exhibit a strongly similar phenotype to the classical, oncogenic Kras-based mouse models of PCa such as Ptf1a-Cre;LSL-Kras ${ }^{G 12 D}$ (KC) and Ptf1a-Cre;LSL-Kras ${ }^{G 12 D}$; $p 53^{R 172 H}(\mathrm{KPC})[16,17]$. Using this model, we applied adjuvant chemotherapy combining gemcitabine with either physostigmine (at $0.2 \times \mathrm{xD}_{50}$, i.e. $160 \mu \mathrm{g} / \mathrm{kg}$, http://datasheets.scbt.com/sc-252784.pdf), or with pyridostigmine $\left(0.2 x \mathrm{LD}_{50}\right.$, i.e. $520 \mu \mathrm{g} / \mathrm{kg}$, http://www.vetpharm.uzh.ch/ reloader.htm?wir/00000015/5975_08.htm?wir/00000015/5 975_00.htm), applied s.c. three times a week. Gemcitabine was administered as 6 repeats of weekly gemcitabine (100 $\mathrm{mg} / \mathrm{kg}$ bodyweight diluted in physiological $\mathrm{NaCl}$ ) intraperitoneally (i.p.), as shown previously [15].

Multiplex enzyme-linked immunosorbent analysis (ELISA) Protein levels of IL-6, IL-10 and TNFalpha were measured in mouse serum via the Luminex $^{\circ}$ MAGPIX $^{\circ}$ multiplex ELISA system (Merck Millipore, Darmstadt, Germany) according to the instructions of the manufacturer.

\section{MTT viability assay}

To assess human PCa cell line growth, the MTT (3-(4, 5-methylthiazol-2-yl)-2, 5-diphenyl-tetrazolium bromide) assay was used. Cells were seeded at a density of 2000 cells/well in a 96-well plate in serum-free RPMI-1640 medium. Treatment of cells with acetylcholine (SigmaAldrich, Taufkirchen, Germany), physostigmine, pyridostigmine or carbachol (all three provided by the internal pharmacy of the Klinikum rechts der Isar) began $12 \mathrm{~h}$ after seeding at the concentration of $10,20,50,100$ or $300 \mathrm{ng}$ per well (in $100 \mu \mathrm{l}$ ) for physostigmine and pyridostigmine, at 100,500 and $1000 \mu \mathrm{M}$ for acetylcholine and at $1 \mu \mathrm{M}, 10 \mu \mathrm{M}, 100 \mu \mathrm{M}$, and $1 \mathrm{mM}$ for carbachol. The viability was measured at $0 \mathrm{~h}, 24 \mathrm{~h}, 48 \mathrm{~h}$ and $72 \mathrm{~h}$ after adding the MTT to each well $(50 \mu \mathrm{g} /$ well $)$ and allowed to incubate for $4 \mathrm{~h}$. The formazan products were solubilized with $100 \mu \mathrm{l}$ of propan-2-ol and the optical density was measured using a photometer at $570 \mathrm{~nm}$.

\section{Cell cycle analysis}

Upon reaching $90 \%$ of confluence, T3M-4 cells were treated with ACh at a concentration of $1000 \mu \mathrm{M}$, physostigmine and pyridostigmine at $30 \mathrm{ng} / \mu \mathrm{l}$ each and the combined agents at $30+30 \mathrm{ng} / \mu \mathrm{l}$. The PCC were then harvested, centrifuged at $200 \times \mathrm{g}$ for $5 \mathrm{~min}$ and washed 2 times using phosphate-buffered saline (PBS). They were then resuspended in $1 \mathrm{ml}$ of ice-cold PBS and added dropwise afterwards to ice-cold absolute ethanol for cell fixation. Cells were fixated for $24 \mathrm{~h}$ at $4{ }^{\circ} \mathrm{C}$, recentrifuged and resuspended in $500 \mu \mathrm{l}$ Triton X-100 (Sigma) in PBS with added $100 \mu \mathrm{g}$ of DNAse-free RNAse A (Sigma) propidium iodide (PI) at a concentration of $20 \mu \mathrm{g} / \mathrm{ml}$. Cells were then incubated for $15 \mathrm{~min}$ at $37^{\circ} \mathrm{C}$ and pipetted afterwards into 96-well plates protected from light for data acquisition. Forward and side scatter was measured using a Guava easyCyte HT Sampling Flow Cytometer.

\section{Immunoblot analysis}

At $90 \%$ confluence, PCa cell lines were lysed and $30 \mu \mathrm{g}$ of protein was separated, electroblotted and the membrane was exposed to monoclonal and polyclonal antibodies (Table 1) at $4{ }^{\circ} \mathrm{C}$ overnight. The equal loading of AChEBlots was assured by re-probing with alpha-Tubulin antibody. The densitometric analysis of the Western Blot was performed via ImageJ (version 1.44p, NIH, USA).

\section{Phospho-kinase profiling}

The Proteome Profiler Human Phospho-Kinase Array Kit (R\&D Systems, Minneapolis, MN, USA) was used to obtain a semiquantitative comparison of the 
Table 1 Primary antibodies. IF: immunofluorescence, WB: Western blot, IHC: immunohistochemistry

\begin{tabular}{|c|c|c|c|c|}
\hline Antibody & Clone & Species & Company & Concentration \\
\hline p44/42 MAPK (Erk1/2) & $137 F 5$ & Rabbit & Cell Signaling, Leiden, The Netherlands & 1:1000 \\
\hline Phospho-p44/42 MAPK (Erk1/2) (Thr202/Tyr204) & $\begin{array}{l}\text { D13.14.4E } \\
\text { XP® }\end{array}$ & Rabbit & Cell Signaling, Leiden, The Netherlands & $1: 1000$ \\
\hline Src & $36 \mathrm{D} 10$ & Rabbit & Cell Signaling, Leiden, The Netherlands & $1: 1000$ \\
\hline Phospho-Src (Ser17) & D7F2Q & Rabbit & Cell Signaling, Leiden, The Netherlands & $1: 1000$ \\
\hline AMPKa & D5A2 & Rabbit & Cell Signaling, Leiden, The Netherlands & $1: 1000$ \\
\hline Phospho-AMPKa (Thr172) & $40 \mathrm{H} 9$ & Rabbit & Cell Signaling, Leiden, The Netherlands & $1: 1000$ \\
\hline p38a MAPK & 7D6 & Rabbit & Cell Signaling, Leiden, The Netherlands & $1: 1000$ \\
\hline Phospho-p38 MAPK (Thr180/Tyr182) & D3F9 XP® & Rabbit & Cell Signaling, Leiden, The Netherlands & $1: 1000$ \\
\hline Anti-Acetylcholine-esterase (AChE) & & Rabbit pAb & Prestige Antibodies ${ }^{\oplus}$, Sigma-Aldrich, Taufkirchen. Germany & $\begin{array}{l}1: 200(\mathrm{IF}) \\
1: 1000(\mathrm{WB}) \\
1: 400(\mathrm{IHC})\end{array}$ \\
\hline Anti-alpha-Tubulin & Ab11034 & Rabbit & Abcam, Cambridge, UK & 1:10.000 \\
\hline $\mathrm{F} 4 / 80$ & Ab6640 & Rat & Abcam, Cambridge, UK & $1: 75$ \\
\hline CD45 & Ab10558 & Rabbit & Abcam, Cambridge, UK & $1: 100$ \\
\hline ChAT & Polyclonal & Rabbit & Kindly provided by Prof. M. Schemann, TU Munich & 1:1000 \\
\hline
\end{tabular}

phosphorylation of 43 different human kinases in T3M4 cells that were either treated with $30 \mathrm{ng} / \mu \mathrm{l}$ physostigmine for $5 \mathrm{~min}$ or untreated, according to the instructions of the manufacturer.

\section{Patients and human tissue}

Tissue samples from patients undergoing pyloruspreserving Whipple's procedure for $\mathrm{PCa}$ of the pancreatic head were collected and processed as described before [18]. A total of 39 patients were included for the survival analyses (for patient characteristics, please see Table 2). A total of 20 patients were used for the correlation analysis between ChAT content in nerves and Union for International Cancer Control (UICC) stage (median age: 61, 11 male, 9 female, UICC stage

Table 2 Patient characteristics. UICC: Union for International Cancer Control

\begin{tabular}{ll}
\hline & N \\
\hline Sex & 39 \\
Male & \\
Female & $22(56.4 \%)$ \\
Age (median; min-max) & $17(43.6 \%)$ \\
UICC & $67.4(31-83)$ \\
UICC Ia & \\
UICC Ib & $3(7.7 \%)$ \\
UICC IIa & $8(20.5 \%)$ \\
UICC IIb & $9(23.1 \%)$ \\
UICC III & $7(17.9 \%)$ \\
UICC IV & $10(25.7 \%)$ \\
\hline
\end{tabular}

distribution: IIA: 4 patients, IIB: 15 patients, III: 1 patient). All patients were informed, and written consent was obtained for tissue collection.

\section{Immunohistochemistry, immunofluorescence, semiquantitative analysis}

Consecutive $3 \mu \mathrm{m}$ sections from formalin-fixed human tissues were incubated with the corresponding antibodies (Table 1 ) overnight in a humid chamber at $4{ }^{\circ} \mathrm{C}$. AChE IHC was detected with the Avidin Biotin Complex Peroxidase Standard Staining Kit (Thermo-Fischer, Waltham, USA). Histopathological analysis was performed by two independent observers (PLP, MJ) followed by resolution of any differences by joint review and consultation with a third observer (IED). Scores of 0-3 were given in 0.5 steps according to the amount of immunoreactivity in each tissue samples. For immunofluorescence staining, Alexa ${ }^{\circledR}$ Fluor 488 and 594 antibodies (Invitrogen, Germany, 1:250 concentration) in combination with 4',6-diamidino-2-phenylindol (DAPI) nuclear stain were utilized.

\section{AChE activity assay}

For comparison of the AChE activity between the human PCa cell lines SU86.86 and T3M4, a colorimetric AChE activity assay kit (Sigma-Aldrich, Taufkirchen, Germany), which is based on the Ellman method, was applied according to the instructions of the manufacturer.

\section{Ethics approval}

All animal studies were conducted according to the national regulations and approved by the Regierung von 
Oberbayern (approval nr. ROB-55.2-2532.Vet_02-16165 and 55.2-1-54-2531-36-08), and Hannover (15/ 1949). The study has been approved by the ethics committee of the Technische Universität München, Munich (approval nr. 154/20).

\section{Statistical analysis}

Results are expressed as mean \pm SD. Two-group analyses were performed using the unpaired t-test for continuous values and with the Mann-Whitney $U$ test for scores and indices. Linear regression was used for correlating tissue expression of $\mathrm{AChE}$ or ChAT with the UICC stages of PCa. Survival analyses were performed with the log-rank test and depicted as Kaplan-Meier curves. All tests were two-sided, and a $p$ value $<0.05$ was considered to indicate statistical significance. All authors had access to the study data and had reviewed and approved the final manuscript.

\section{Results}

Pancreatic cancer cells express high amounts of AChE

The role of $\mathrm{ACh}$ as a neurotransmitter in the parasympathetic nervous system (PSNS) is well-known, but its non-neuronal function as a local signaling molecule that influences basic cell functions such as apoptosis and proliferation, is often underestimated [9]. The cholinergic system comprising $\mathrm{ACh}$ and its synthesizing enzyme, choline acetyltransferase (ChAT), as well as its degrading enzyme, acetylcholinesterase (AChE), have been detected in several cancer entities, such as colon, liver and lung cancer $[11,13,19]$. However, the amount of AChE expression in PCa has not been genuinely analyzed before. By employing immunostaining against AChE, we demonstrated mild to weak staining in normal acinar cells, pancreatic islets and intrapancreatic nerves (Fig. 1a-c). Notably, immunostaining increased in precursor lesions of $\mathrm{PCa}$, i.e. pancreatic intraepithelial neoplasia (PanIN) lesions (Fig. 1d-f). The strongest staining was found in areas of invasive ductal adenocarcinoma with prominent staining localized in the peri- and sub-membranous cell compartment of cancer cells (Fig. 1g-i). Combined staining of AChE and the PCa cell marker Cytokeratin 19 (CK19) using double-immunofluorescence (IF) staining confirmed strong co-localization of CK19 with AChE (Fig. 1g-l), underlining the specificity of AChE expression in cancer cells.

In order to further quantify the expression of $\mathrm{AChE}$ in PCa cells (PCC), we isolated dorsal root ganglia (DRG) from postnatal C57BL/6 J mice. DRG neurons incorporate afferent neuronal signals of different qualities and express AChE [20]. Here, immunoblot analysis of commonly used human PCC lines, T3M-4, SU.86.86 and Panc-1, as well as colon carcinoma cell lines SW620 and DLD-1, and the glioblastoma cell line LN229, revealed high levels of AChE expression when compared to DRG of C57BL/6 J mice (Fig. 1m-n). Collectively, these results demonstrate that PCCs express high amounts of $\mathrm{AChE}$ in a specific manner.

\section{AChE inhibition suppresses PCC growth in vitro}

Next, we sought to explore the effect of AChE inhibition on cancer cell growth. Administration of physostigmine or pyridostigmine, two commonly used AChE inhibitors, led to significant inhibition of viability in T3M-4, but not in SU86.86 cells (T3M-4-physostigmine: $189 \pm 99 \%$ with $0.1 \mathrm{ng} / \mu \mathrm{l}$ vs. $217 \pm 110 \%$ with solvent with $0.1 \mathrm{ng} / \mu \mathrm{l}$; T3M-4-pyridostigmine: $191 \pm 90 \%$ with $3 \mathrm{ng} / \mu \mathrm{l}$ vs. $220 \pm$ $117 \%$ with solvent, Fig. 2a-f). Similarly, following administration of acetylcholine (ACh), or of carbachol, a direct muscarinic receptor agonist, a dose-dependent growth reduction was evident for both cell lines (ACh-T3M-4: $242 \pm 165 \%$ with $1000 \mu \mathrm{M}$ vs. $384 \pm 374 \%$ with solvent; ACh-SU86.86: $212 \pm 116 \% \mathrm{ng} / \mu \mathrm{l}$ with $1000 \mu \mathrm{M}$ vs. $297 \pm$ $220 \%$ with solvent; Carbachol-T3M-4: $348 \pm 285 \%$ with $100 \mu \mathrm{M}$ vs. $511 \pm 391 \%$ with solvent, Carbachol-SU86.86: $260 \pm 145 \%$ with $100 \mu \mathrm{M}$ vs. $421 \pm 270 \%$ with solvent, Fig. 2c \& f-h). To exclude a difference in the basal AChE activity of the cell lines SU86.86 and T3M4, we performed a colorimetric AChE activity assay based on the Ellman method, which revealed no difference in the basal AChE activity of the two cell lines (Fig. 2i). These results confirmed that non-neuronal cholinergic signaling decelerates PCC growth in vitro, which was achieved through increasing ACh availability, through AChE inhibition, or through direct muscarinic stimulation.

\section{Cholinergic activation inhibits PCC invasion in vitro and in vivo}

In order to test the effect of AChE inhibition in PCCs on their invasive potential, we performed Matrigel-based invasion assays with SU86.86 cells (Fig. 2j-1). Also here, in a dose dependent manner, physostigmine inhibited invasion when applied at the concentration of $30 \mathrm{ng} / \mu \mathrm{L}$ (70.4 $\pm 21.6 \%$ of control, Fig. 2i). Pyridostigmine inhibited PCC invasion at intermediate and high concentrations of $10 \mathrm{ng} / \mu \mathrm{L}(71.4 \pm 23.4 \%$ of control) and $30 \mathrm{ng} / \mu \mathrm{L}$ ( $45.5 \pm 13.0 \%$ of control), respectively (Fig. $2 \mathrm{k}$ ), and ACh limited invasion significantly at the higher concentration of $1000 \mu \mathrm{M}$ (43.2 $\pm 26.6 \%$ of control, Fig. 2l). Collectively, these findings indicated that both AChE inhibition and direct cholinergic activation through $\mathrm{ACh}$ inhibit $\mathrm{PCa}$ cell invasion in vitro.

In order to test whether indirect cholinergic activation also reduces pancreatic cancer growth in vivo in animals with intact vagal innervation, we utilized a xenograft mouse model, which was generated by injecting PCC into Crl:NMRI-Foxn1 ${ }^{\text {nu/nu }}$ nude mice. The effect of AChE inhibition was investigated in a prophylactic and a 

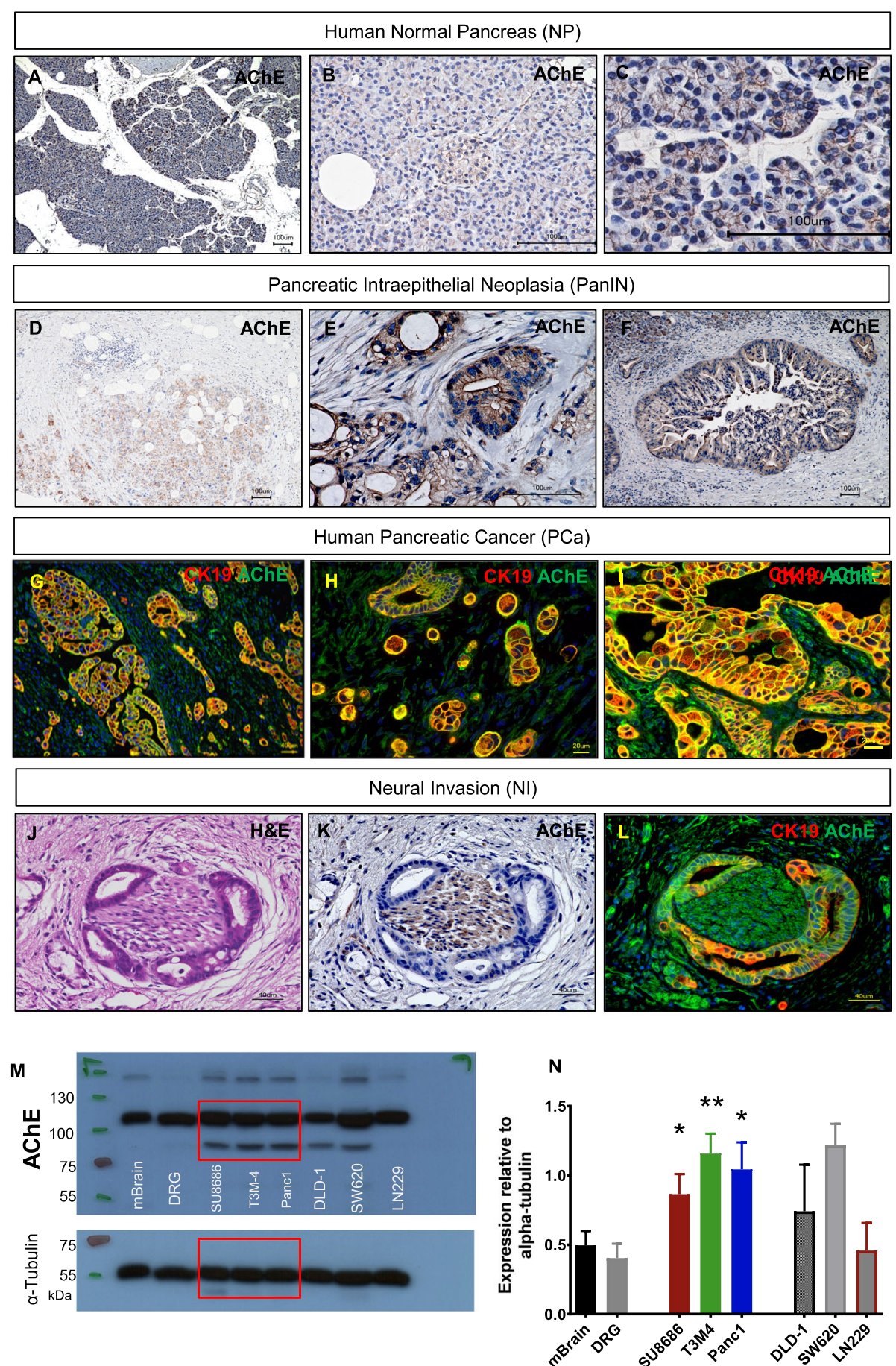

Fig. 1 Acetylcholinesterase (AChE) expression in normal pancreas (NP), pancreatic intraepithelial neoplasia (PanlN) and pancreatic cancer (ductal adenocarcinoma/PCa). a-c Representative immunohistochemical (IHC) photomicrographs of AChE-immunostained normal human pancreas. $\mathbf{d}$-f Representative images showing IHC staining of AChE in PanIN Grade 3 lesions. g-i Double-immunofluorescence staining for CK-19, AChE and DAPI in pancreatic cancer. $\mathbf{j}-\mathbf{l}$ Representative images of double-immunofluorescence staining for CK-19, AChE and DAPI at sites of (peri)neural invasion in human pancreatic cancer specimens. $\mathbf{m}$ Immunoblot analysis of AChE (110 kDa \& $76 \mathrm{kDa})$ in mouse brain (mBrain) and mouse dorsal root ganglia (mDRG) mouse as control tissue, in human pancreatic cancer (PCC)-lines (T3M-4, SU.86.86 and Panc-1) as well as colon carcinoma cell lines SW620 and DLD-1 and the glioblastoma cell line LN229. $\mathbf{n}$ Densitometry graph depicts the quantification of AChE signal relative to alpha-Tubulin content in mDRG, SU.86.86, T3M-4 and Panc1 ( $n=3$ biological replicates), (SU.86.86 $p=0.0112 ;$ T3M-4 $p=0.0018 ;$ Panc1 $p=0.0074)$. Results depicted as Mean \pm SD. ${ }^{*} p<0.05,{ }^{* *} p<0.01$ 

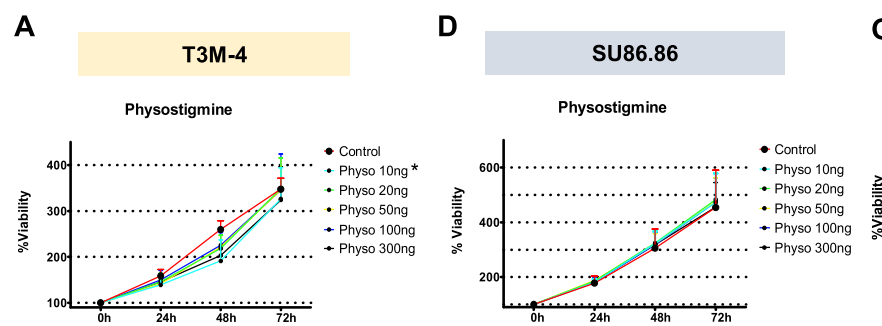

G

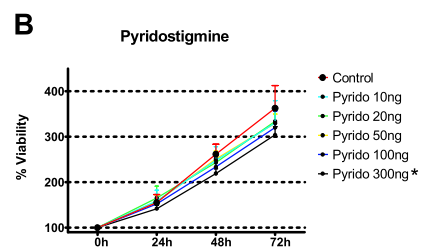

E
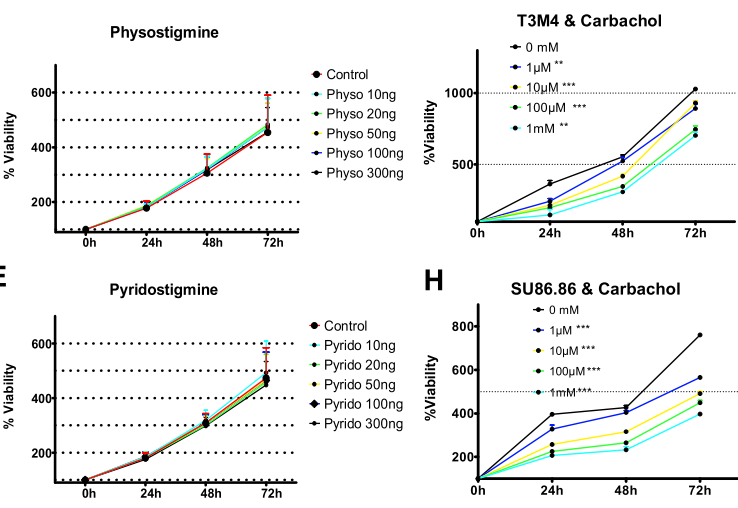

H

H SU86.86 \& Carbachol

C

$\mathbf{F}$
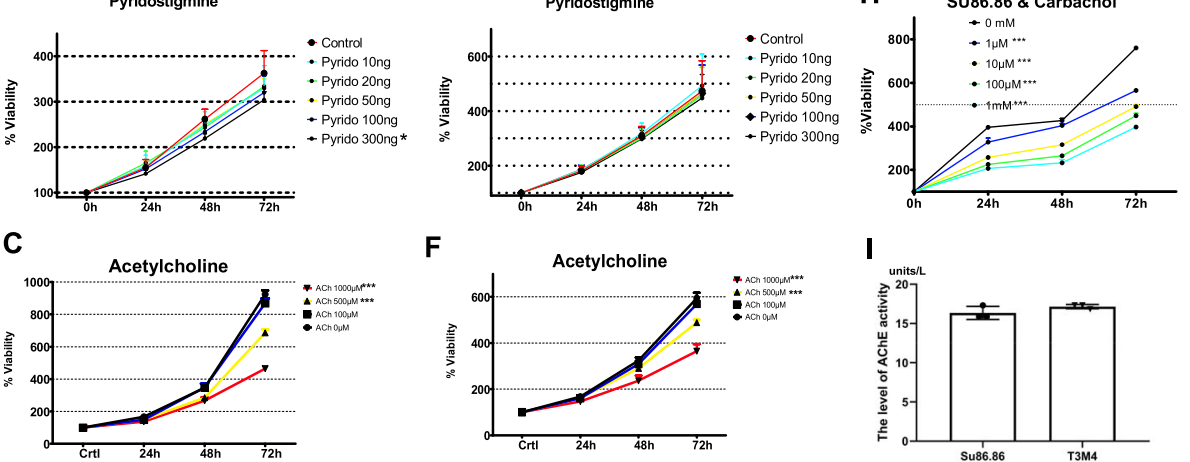

I
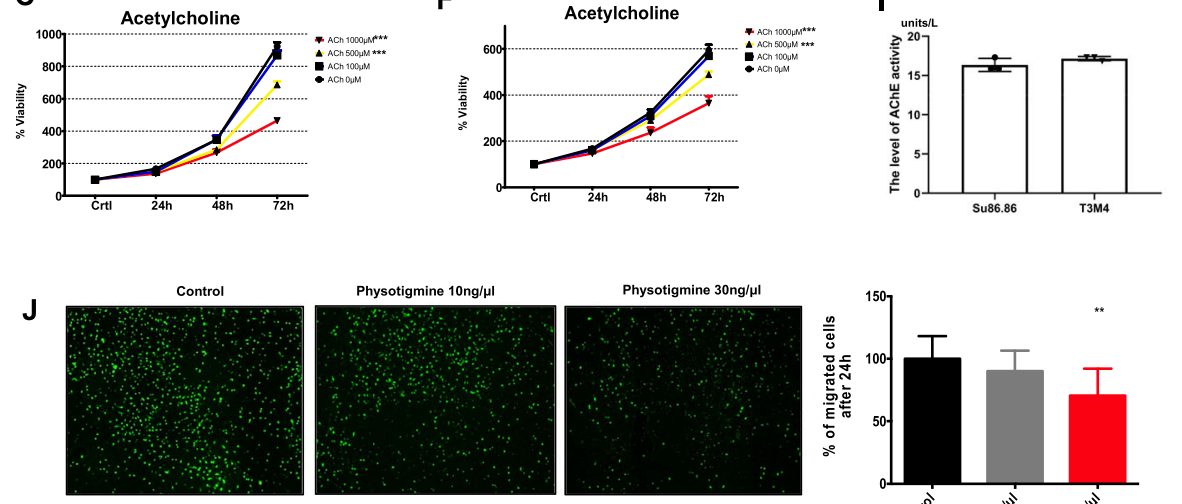

Physotigmine 10ng/pl

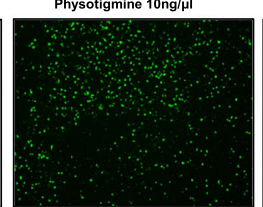

Physotigmine 30ng/ul
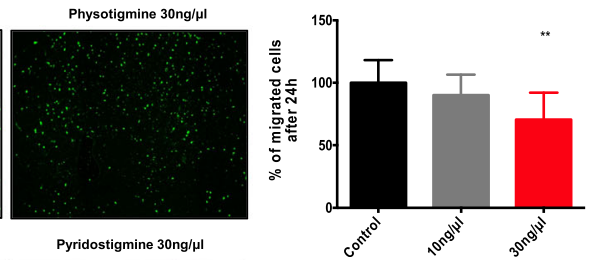

K

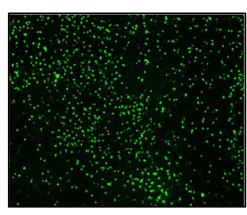

Pyridostigmine 10ng//

Pyridostigmine 30ng/ $/ \mathrm{ll}$
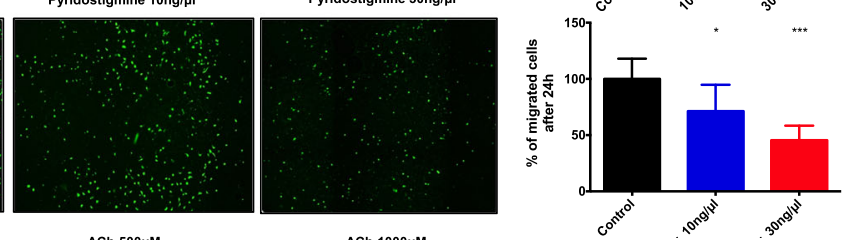

L

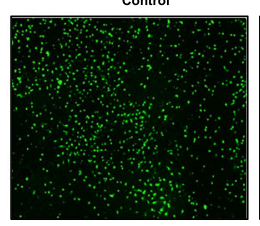

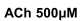

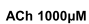
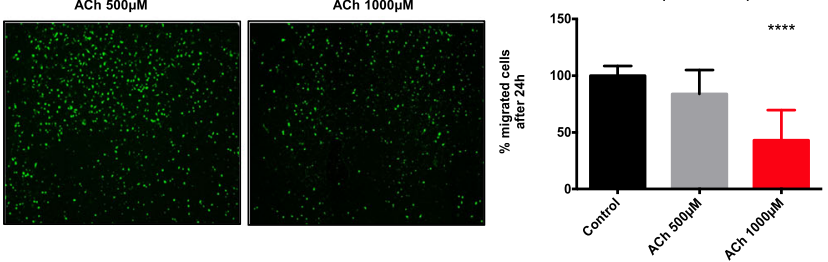

Fig. 2 AChE inhibition suppresses PCC proliferation and invasion in vitro. a-h T3M-4 and SU86.86 human pancreatic cancer cells (PCCs) were treated for $24 \mathrm{~h}, 48 \mathrm{~h}$ and $72 \mathrm{~h}$ with indirect parasympathomimetic drugs (physostigmine, pyridostigmine), with the direct parasympathomimetic carbachol or with acetylcholine (ACh) and analyzed for their viability via MTT assay, Graphs shows cell growth of human PCCs over time and area under curve (AUC) values for different treatment regimens (T3M-4: physostigmine/Physo $10 \mathrm{ng}:{ }^{*} p=0.0153$; pyridostigmine/Pyrido $300 \mathrm{ng} /$ $100 \mu$ l:* $p=0.0175$; for ACh: T3M-4 and SU86.86: $500 \mu \mathrm{M}{ }^{* *} p<0.0001 ; 1000 \mu \mathrm{M}{ }^{* *} p<0.0001 ;$ T3M-4-carbachol: $1 \mu \mathrm{M}:{ }^{* *} p=0.0011,10 \mu \mathrm{M}:{ }^{* *} p<$ 0.0001, $100 \mu \mathrm{M}:{ }^{* *} p<0.0001,1 \mathrm{mM}:{ }^{* *} p<0.0022$; SU86.86-carbachol: ${ }^{* *} p=0.0011$, unpaired t-test of area under the curve/AUC). i AChE activity assay with the SU86.86 and T3M4 cell lines. $\mathbf{j}$-I Representative photomicrographs of transwell chamber membranes with CFSE-stained SU86.86 PCCs after treatment with physostigmine, pyridostigmine or ACh. Graphs shows the percentage of treated migrated cells compared to solventtreated treated controls (Physostigmine. $30 \mathrm{ng} / \mu \mathrm{l}{ }^{*} p=0.0102$ by unpaired t-test; pyridostigmine: $10 \mathrm{ng} / \mu \mathrm{l}{ }^{*} p=0.0162 ; 30 \mathrm{ng} / \mu l^{* * * *} p<0.0001 ; A C h$ : ${ }^{* * * *} p=0.0006$; by unpaired t-test). All experiments were performed in biological triplicates

therapeutic treatment group (Fig. 3a). Both groups received daily subcutaneous injections of low- or highdose physostigmine or pyridostigmine. The prophylactic treatment arm started simultaneously with tumor induction, whereas therapeutic treatment started 1 week after tumor induction. After a 4-week injection period, tumor size was assessed. A significant decrease in the tumor size was observed in animals that received 
A

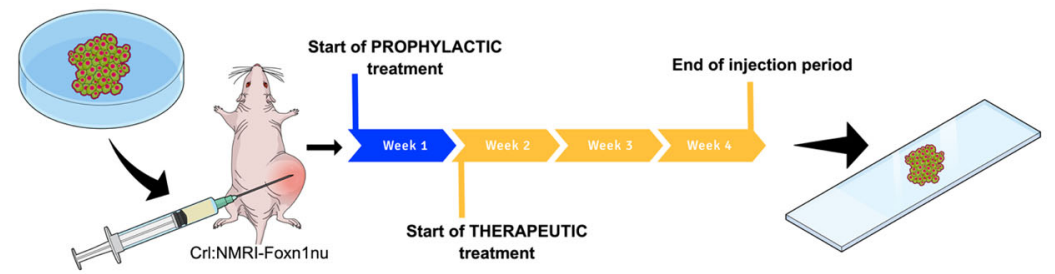

B

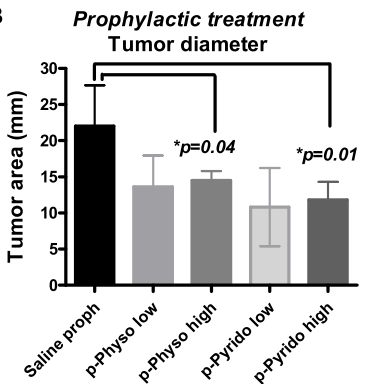

E
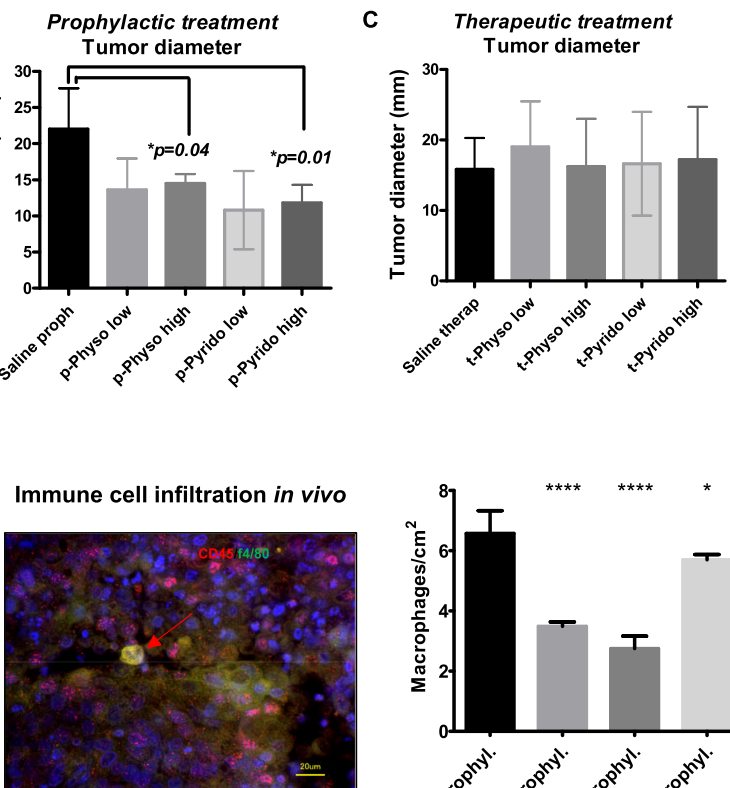

D

Invasion in vivo

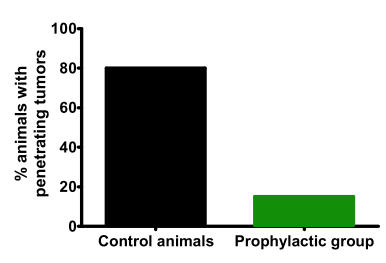

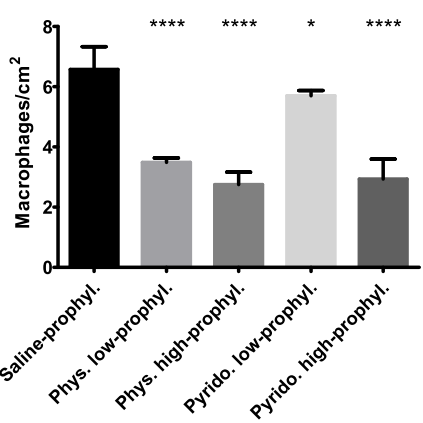

$\mathbf{F}$
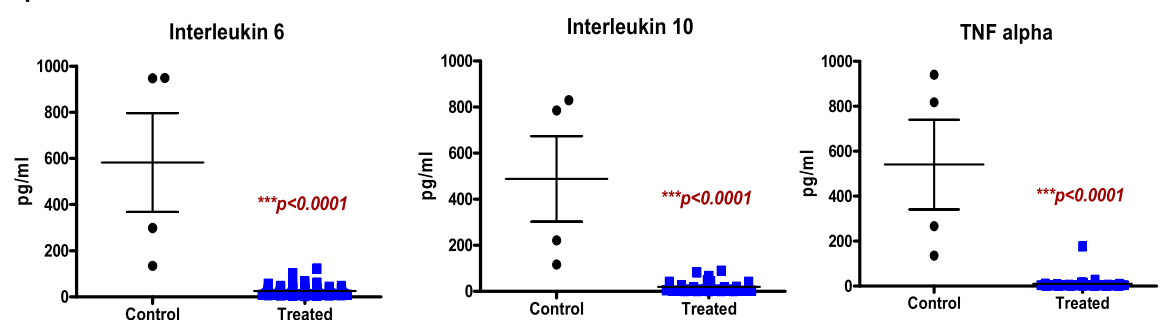

Fig. 3 Acetylcholinesterase (AChE) inhibition attenuates the formation of xenografted PCa in mice and decreases tumor-associated inflammation. a In vivo xenograft model: human T3M-4 pancreatic cancer cells were transplanted subcutaneously into Crl:NMRI- ${ }^{\text {Foxn } 1 n u / n u}$ mice that were treated prophylactically or therapeutically, the latter beginning at 1 week after tumor induction. Physostigmine and pyridostigmine were administered daily s.c. at $0.1 \times L_{50}$ (low dose) or $0.3 \times L_{50}$ (high dose), and Pyridostigmine at $0.2 \times L_{50}$ (low dose) and $0.4 \times L_{50}$ (low dose)or saline injection (control). b Prophylactic treatment with physostigmine or pyridostigmine resulted in a reduction of the xenografted tumor mass (means $\pm \mathrm{SD}$ ). c Therapeutic treatment with AChE inhibitors in mice xenografted with T3M-4 cells. $\mathbf{d}$ show the percentage of animals that had invasive penetrating tumor growth (Control animals $8 / 10=80 \%$ and prophylactically treated animals $6 / 40=15 \%$ ) e Representative IF photomicrograph of double-positive tumor-associated macrophages (TAMs) stained with CD45, f4/80 and DAPI. Graph shows the amount of double-positive cells per square centimeters of tumor tissue compared to the untreated animals $\left({ }^{* * *} p<0.0001\right.$ for Phys. low-prophyl., Phys. highprophyl., and Pyrido. high prophyl. Respectively; Pyrido. low-prophyl. ${ }^{*} p=0.0370$ by unpaired t-test). Means \pm SEM. ${ }^{*} p<0.05 ;{ }^{* * *} p<0.001$; **** $p<0.0001$ ). $\mathbf{f}$ Comparative analysis of cytokine levels in the serum of physostigmine or pyridostigmine treated, xenografted mice ("treated") in comparison with control/saline treated mice ("control"). The results of prophylactically and therapeutically treated animals have been pooled in the graphs 
physostigmine or pyridostigmine prophylactically $(\mathrm{p})$ in a dose-dependent manner (Control /saline $=22.0 \pm 5.7$ $\mathrm{mm}$ vs. p-physo-high $=14.5 \pm 1.3 \mathrm{~mm}$ vs. p-pyridohigh $=11.8 \pm 2.5 \mathrm{~mm}$, Fig. 3b). However, therapeutic administration of these indirect parasympathomimetics to established xenograft tumors did not influence tumor size over the course of the treatment (Fig. 3c). In order to evaluate the invasive potential of PCC in vivo, we assessed the proportion of xenografted mice that showed penetrating tumor growth into neighboring organs, i.e. kidneys and lungs, following therapeutic or prophylactic treatment with AChE-blockers. In animals in which AChE was blocked prophylactically, only $15 \%$ of the specimens showed penetrating tumor growth, whereas $80 \%$ of the control group showed tumor infiltration into neighboring organs (Fig. 3d, Supplementary figure 1). These findings suggested a partially tumor-suppressing effect of non-neuronal cholinergic activation in vivo, yet only in the context of developing tumors.

\section{Indirect parasympathomimetic agents suppresses immune cell infiltration by tumor-associated macrophages (TAM) and reduce serum cytokine levels in xenografted PCa mice}

Non-neuronal cholinergic signaling is also involved in the regulation of the immune system as most immune cells express ACh, AChE, and muscarinic receptors [21]. In this context, we aimed to analyze if indirect cholinergic activation not only has a direct cancer-suppressive effect, but also modulates the immune response in the tumor microenvironment. Therefore, we quantified tumor-associated macrophage (TAM) amounts in pancreatic tumors of the xenograft mouse model. Tumorassociated macrophages are a subpopulation of cytokinesecreting monocytes and have been implicated in playing an important role in the tumor microenvironment (TME). Upon activation, TAM differentiate into M1 or M2 polarized macrophages and release abundant cytokines [22]. Here, we performed double-IF for the murine macrophage marker f4/80 and CD45 (Fig. 3e). Our analysis demonstrated a reduction of $\mathrm{CD} 45^{+} / \mathrm{f} 4 / 80^{+}$- TAM infiltration in murine tumors of physostigmine or pyridostigmine treatment groups (Saline-prophl.: $6.6 \pm 0.8$ cells $/ \mathrm{cm}^{2}$, Physostigmine-high: $2.7 \pm 0.4$ cells $/ \mathrm{cm}^{2}$, Pyridostigmine-high: $2.9 \pm 0.7 \mathrm{cells} / \mathrm{cm}^{2}$, Fig. 3e). As cholinergic activation is known to exert a systemic antiinflammatory effect ("the cholinergic anti-inflammatory pathway"), we then assessed the serum levels of the cytokines interleukin 6 (IL6), interleukin 10 (IL10) and tumor necrosis factor-alpha (TNFalpha) in the xenografted mice (Fig. 3f). Here, we detected a massive suppression of the levels of all these cytokines in all treated groups, regardless of the dosage of treatment, when compared to saline-treated controls (IL6 control:
$582.8 \pm 428.0 \mathrm{pg} / \mathrm{ml}$, IL6 treated: $25.4 \pm 21.5 \mathrm{pg} / \mathrm{ml}$; IL10 control: $488.2 \pm 371.6 \mathrm{pg} / \mathrm{ml}$, IL10 treated: $19.4 \pm 26.1 \mathrm{pg} /$ $\mathrm{ml}$; TNFalpha control: $540.2 \pm 398.4 \mathrm{pg} / \mathrm{ml}$, TNFalpha treated: $10.4 \pm 29.3 \mathrm{pg} / \mathrm{ml}$, Fig. 3f). Collectively, these data suggested a prominent suppression of tumorassociated local and systemic inflammation markers in the xenografted PCa mice upon physostigmine or pyridostigmine treatment.

\section{Cholinergic activation leads to intracellular p-ERK1/2 and p-p38 MAPK inhibition and induces cell cycle arrest}

In order to determine molecular mechanisms responsible for growth and invasion inhibition in PCC upon AChE inhibition, we performed a phospho-kinase antibody array for screening that enables the profiling of 43 different human kinases in two experimental arms (Fig. 4a-b). Here, we compared intensity of phosphorylation of these multiple kinases in T3M4 cells treated with either physostigmine or left untreated, and used the clues from this initial screen for subsequent validation analyses. Among well described mitogen-activated protein kinases (MAPK) that are known to be widely expressed in $\mathrm{PCa}$ and involved in cell proliferation, invasion, cell-survival and cell cycling, we found extracellularly regulated kinase 1 and 2 (ERK1/2), p38, protooncogene tyrosine-kinase Src (Src) and 5'-AMP-activated protein kinase $\alpha(\mathrm{AMPK} \alpha)$ to be altered under the treatment (Fig. 4a-c) [23]. In validation immunoblots with T3M-4 cells, we confirmed the decrease in phosphorylated ERK1/2 (pERK) levels, particularly after treatment with high-dose pyridostigmine $(61.5 \pm 13.9 \%$ of control). This effect was more pronounced for SU86.86 cells, which, after treatment with physostigmine or pyridostigmine, exhibited even more obviously diminished pERK1/2 levels in a dose-dependent manner at both mid-level and high concentrations (physostigmine-mid: $80.5 \pm 2.6 \%$ of control, physostigmine-high: $69.2 \pm 7.9 \%$ of control, pyridostigmine-mid: $70.2 \pm 8.2 \%$ of control, pyridostigmine-high: $60.3 \pm 11.8 \%$ of control, Fig. $4 \mathrm{e}$ ). As an essential component of the MAPK signal transduction pathway, p38 reacts to extracellular stimuli and mediates cellular responses [24, 25]. In our experiments, phosphorylation of p38 was abolished upon administration of low $(43.7 \pm 8.2 \%$ of control), mid- $(53.4 \pm 17.3 \%$ of control) and high (69.3 $\pm 10.9 \%$ of control) physostigmine concentrations, but not via pyridostigmine (Fig. 4f). However, following treatment with either of these drugs, there was no significant change in the amount of intracellular p-Src nor p-AMPK $\alpha$ (Fig. 4g-h). In summary, our experiments demonstrated that inhibition AChE reduced ERK phosphorylation.

To investigate whether cell cycle progression of PCC is also affected by AChE inhibition, we performed a propidium iodide-(PI-) based, flow cytometric cell cycle 
analysis (Fig. 4i-j). After administering ACh, significantly more PCCs were observed in the G1/0 phase (ACh: $56.1 \pm 3.2 \%$ vs. Control: $47.8 \pm 0.9 \%)$ and fewer cells in the S-phase (ACh: $10.0 \pm 0.1 \%$ vs. Control: $13.0 \pm 0.8 \%$, Fig. 4i-j). Physostigmine did not alter G1/0-phase amount, but reduced S-Phase cell-count $(8.4 \pm 1.7 \%)$, and pyridostigmine enhanced G1/0-phase count (55.3 \pm $1.5 \%$ ), but did not alter the S-Phase cell count (Fig. 4i-j). No significant difference in cell count was noted for cells in G2/M-Phases, however following all treatments a trend towards lower cell counts was observed. Overall, we thus detected a cell cycle arrest in G1/0 phase following AChE inhibition.

\section{Adjuvant indirect cholinergic treatment does not impact survival in a resectable PCa mouse model}

In order to translate our findings into a clinically relevant setting, we used a novel R0-resectable, genetically induced PCa mouse model [15]. In this model, plasmids containing the Sleeping Beauty (SB) transposase SB13, a Kras-G12V encoding transposon, and the Cre recombinase were injected and electroporated into the pancreatic

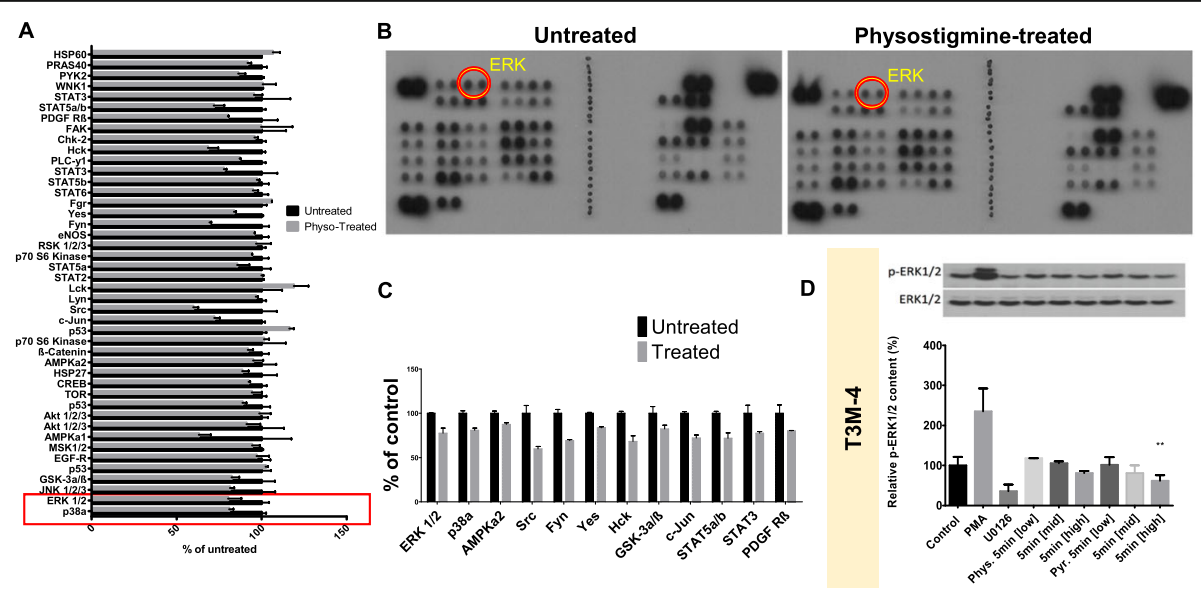

E

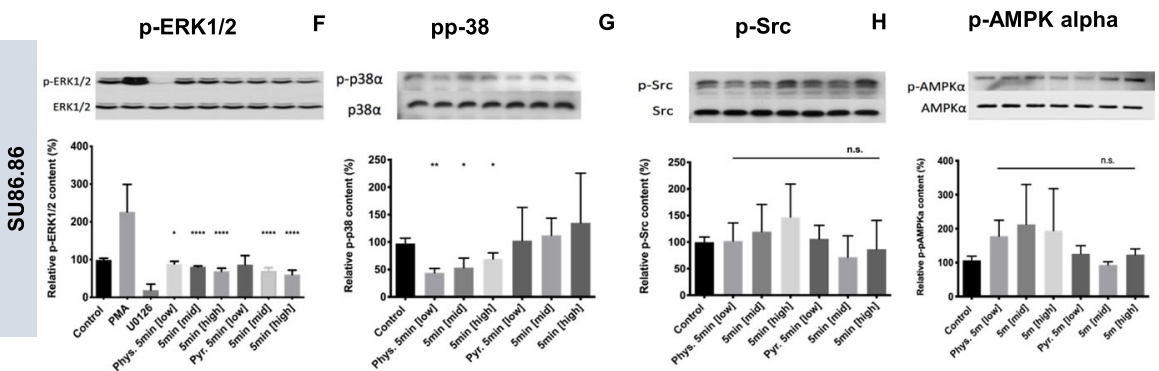

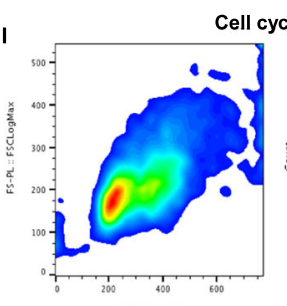
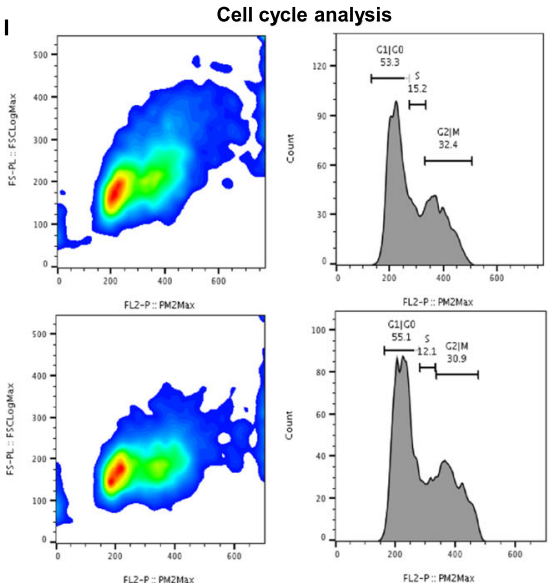

$J$

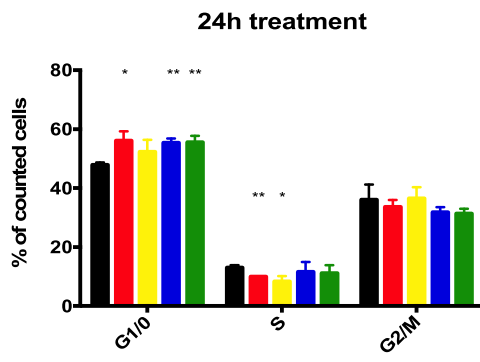

Cycle phase

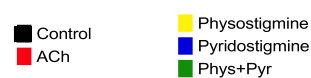

Fig. 4 (See legend on next page.) 
(See figure on previous page.)

Fig. 4 AChE inhibition suppresses ERK \& p38 phosphorylation and inhibits cell cycle progression. a Bar chart depiction of differences in the signal intensity of various kinases from the human phosphokinase screen in T3M4 cells treated with physostigmine (physo) vs untreated controls. b-c Representative dot blots and selected bar graphs from the human phosphokinase screen in T3M4 cells treated with physostigmine (physo) vs untreated controls. d Western Blot analysis of phosphorylated ERK (pERK)/ERK in T3M-4 cells after 5 min-treatment with phorbol 12-myristate 13acetate (PMA, an ERK-activator/positive control, Sigma-Aldrich, Taufkirchen, Germany), U0126 (a MEK-inhibitor/negative control, Sigma-Aldrich, Taufkirchen, Germany), physostigmine/Phys and pyridostigmine/Pyr at low, middle and high concentrations ( $1 \mathrm{ng} / \mu \mathrm{l}, 10 \mathrm{ng} / \mu \mathrm{l}$ and $30 \mathrm{ng} / \mu \mathrm{l}$, respectively). Graph shows quantification of the densitometry of immunoblot for phosphorylated ERK (pERK)/ERK shown in percent of expression compared to control (Pyr. 5 min [high] ${ }^{* *} p=0.004$ by unpaired t-test). e-h Western Blot analysis of phosphorylated ERK (pERK)/ERK, of phosphorylated p38 (pp38)/p38, phosphorylated Src (pSrc)/Src and phosphorylated AMPKa (pAMPKa)/AMPKa in SU86.86 cells after 5 mintreatment with phorbol 12-myristate 13-acetate (PMA, an ERK-activator/positive control, Sigma-Aldrich, Taufkirchen, Germany), U0126 (a MEKinhibitor/negative control, Sigma-Aldrich, Taufkirchen, Germany), physostigmine/Phys and pyridostigmine/Pyr at low, middle and high concentrations $(1 \mathrm{ng} / \mu \mathrm{l}, 10 \mathrm{ng} / \mu \mathrm{l}$ and $30 \mathrm{ng} / \mu \mathrm{l}$, respectively). Graphs shows quantification of the densitometry of immunoblots (pERK: Phys. 5 min [low] ${ }^{*} p=0.0109$; Phys. 5 min [mid], Phys 5 min [high], Pyr. 5 min [mid] and Pyr. 5 min [high] ${ }^{* * *} p<0.0001$ by unpaired t-test; pp38: Phys. 5 min [low] ${ }^{*} p=0.0019$; Phys. 5 min [mid] ${ }^{*} p=0.0189$; Phys. 5 min [high] ${ }^{*} p=0.0302$ by unpaired t-test). n.s.: not significant. i Scatter plot of propidium iodide (PI) signal in T3M4 PCC untreated (upper graph) and treated (lower graph) with $30 \mathrm{ng} / \mu \mathrm{l}$ of physostigmine and their corresponding cell count plot. $\mathbf{j}$ shows cell count distribution throughout G1/0-, S- and G2/M-phases of T3M-4 cells. G1/0: ACh $1000 \mu M{ }^{*} p=0.0122$, Pyridostigmine $30 \mathrm{ng} / \mu{ }^{* *} p=0.0017$, Phys. + Pyr. $15 \mathrm{ng} / \mu \mathrm{l}+15 \mathrm{ng} / \mu \mathrm{l}{ }^{* *} p=0.0046 ;$ S: ACh $1000 \mu \mathrm{M}{ }^{* *} p=0.0033$, Physostigmine $30 \mathrm{ng} / \mu \mathrm{l}{ }^{*} p=0.0139$ by unpaired t-test). Mean \pm SD. ${ }^{*} p<0.05,{ }^{* *} p<0.01,{ }^{* * *} p<0.0001$

tail of p53floxed mice $\left(p 53^{f l f l}\right)$ via mini-laparotomy [15]. Upon activation of the Cre recombinase, tumor formation was initiated in a local fashion (the Pfl model), which is in contrast with the multilocular tumor growth of classical genetically induced mouse models of $\mathrm{PCa}$ (Fig. 5a-b). Three weeks after the tumor induction, the animals developed macroscopically visible tumors. After pancreatic tail resection, mice received adjuvant chemotherapy with gemcitabine. Here, mice of the Pflgenotype exhibited a median survival of 41 days (Fig. $5 \mathrm{c}$ ). When adjuvant gemcitabine treatment was combined with physostigmine, median survival was 32 days. Combinational therapy with gemcitabine and pyridostigmine was associated with a median survival to 39 days (Fig. $5 \mathrm{c}-\mathrm{d})$. The most common reason for death was combined local and distant (hepatic or peritoneal) recurrence. Thus, the $\mathrm{AChE}$ inhibitors did not generate any additive survival benefit in this innovative, adjuvant therapy setting.

\section{Correlation of tissue AChE and ChAT expression with clinicopathological variables in human PCa}

Lastly, to compare our findings from this translational mouse model to human $\mathrm{PCa}$, we analyzed the expression patterns of $\mathrm{AChE}$ and the $\mathrm{ACh}$ synthesizing enzyme ChAT in human PCa tissues $(n=39)$ by semiquantitive immunostaining scores and correlated to clinicopathological variables of the corresponding patients. Furthermore, high vs. low scores of AChE immunostaining (separated by the median score) did not result in any difference in the overall survival rate of the PCa patients (Fig. 5e). Accordingly, tissue expression scores of AChE did not associate with different UICC tumor stages (Fig. 5f). Interestingly, higher tumor grades, i.e. a poor tumor differentiation, were associated with significantly lower AChE IHC scores (G1: $1.5 \pm 0.2$, G2: $1.1 \pm 0.3$, G3: $1.0 \pm$
0.4, Fig. 5g), suggesting a spontaneous loss of AChE in increasingly aggressive $\mathrm{PCa}$. This was surprising, as we originally hypothesized that high $\mathrm{AChE}$ expression, i.e. diminished cholinergic input, would be associated with worse survival and poor differentiation. As this was not the case, we quantified the expression level of choline acetyltransferase enzyme (ChAT), which catalyzes the formation of acetylcholine, in the nerves of these tissues via immunohistochemical scoring. Correlation of ChAT expression levels to tumor stage revealed that high expression levels ChAT were indeed associated with low tumor stages $\left(r^{2}: 0.20, p=0.049\right.$, Fig. 5h). Hence, we concluded that advanced tumor stages were characterized by low cholinergic input due to low ChAT expression, and yet also by suppression of the degrading enzyme AChE. This simultaneous suppression of the AChsynthesizing and ACh-degrading intrinsic mechanisms in PCa may explain the lack of a prognostic effect of tumor AChE levels in established mouse and human PCa.

\section{Discussion}

The present study suggested an anti-proliferative and anti-invasive effect of non-neuronal cholinergic signaling in pancreatic cancer. Inhibition of endogenous, nonneuronal AChE decelerated PCC growth and invasiveness in vitro \& in vivo, which was linked to intracellularly reduced MAPK phosphorylation and reduced downstream phosphorylation of ERK1/2 and p38. Furthermore, prophylactic cholinergic activation in $\mathrm{PCa}$ mouse models with intact vagal innervation reduced both tumor invasiveness in vivo and immune cell infiltration by tumor-associated macrophages. However, administration of parasympathomimetic agents as coadjuvant therapy together with gemcitabine did not influence the overall survival of mice in a resectable, 


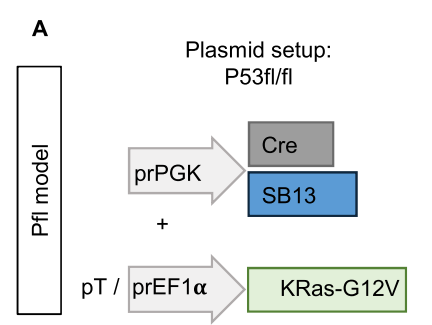

B $\quad$ p53 fl/fl mice
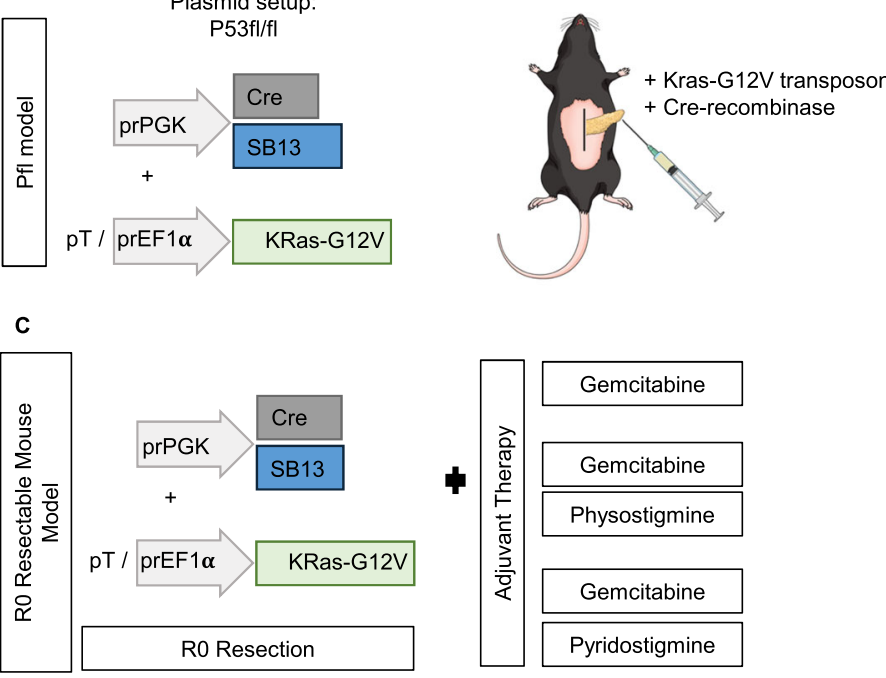

Median Survival

$<29-37$ days

D

Survival in the Ro resectable mouse model

+ Gemcitabine+Physostigmine
$\perp$ G Gemcitabine+Pyridostigmine

E

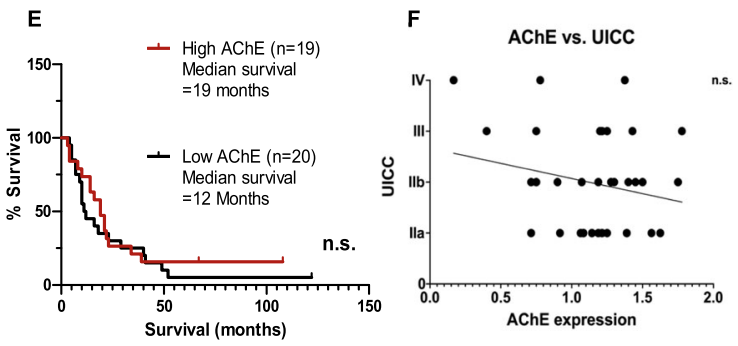

G

H

ChAT UICC
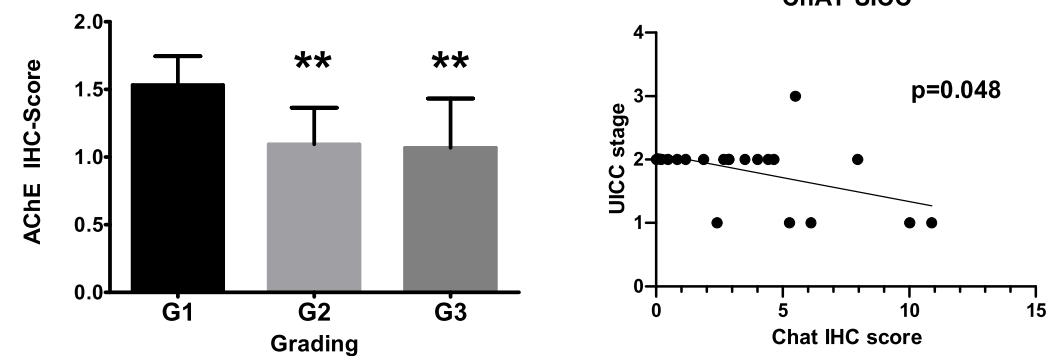

Fig. 5 Clinical impact of AChE in the RO resectable, transgenic pancreatic cancer mouse model and in human PCa. a-b Plasmids containing the Sleeping Beauty (SB) transposase SB13, a Kras-G12V encoding transposon, and the Cre recombinase were injected and electroporated into the pancreatic tail of p53floxed mice $\left(p 53^{f / f f}\right)$. (Pfl model). For details on plasmid constructs, please refer to [15]. c-d After pancreatectomy and adjuvant chemotherapy with gemcitabine, mice of the Pfl-genotype exhibited a median survival of 41 days. Combinational therapy of pancreatectomy with adjuvant gemcitabine and physostigmin led to a median survival of 32 days, and with adjuvant gemcitabine and pyridostigmine to 39 days (n.s.: not significant). e Survival rate of PCa patients with high $(n=19)$ and low $(n=20)$ AChE presence based on median immunohistochemistry/IHC-Score (n.s., log-rank test.). Kaplan-Meier analysis did not reveal a significant difference in survival between both groups. $\mathbf{f}$ Correlation analysis (linear regression) of cancer tissue AChE expression based on semiquantitative IHC score and UICC tumor stage (n.s.: not significant). $\mathbf{g}$ Correlation of semiquantitative immunohistochemistry (IHC) scores for AChE expression and tumor grading (G1-G3). (G1 vs. G2 ${ }^{* *} p=0.018 ; \mathrm{G} 1$ vs. G3 ${ }^{* *} p=0.015$; Mann-Whitney U test). $\mathbf{h}$ Correlation analysis (linear regression) of ChAT expression within nerves of human PCa tissues based on semiquantitative IHC score and UICC tumor stage. Graph shows a negative correlation between ChAT expression and tumor stage, indicating that low ChAT expression is correlated to higher tumor stages, while high ChAT expression correlates to low tumor stages $\left(r^{2}=0.1988, p=0.048\right)$

transgenic mouse model of unilocular genetic PCa. Accordingly, AChE did not correlate to survival in human $\mathrm{PCa}$ and was actually suppressed in parallel with ChAT in higher grade tumors. Therefore, our study suggests that for targeting $\mathrm{PCa}$, direct cholinergic stimulation of the muscarinic signaling, rather than indirect activation 
via $\mathrm{AChE}$ blockade, may be a more effective therapeutic strategy.

Various studies have previously reported a cancerpromoting effect of the vagus nerve. In a mouse model of gastric cancer, surgical vagotomy decreased gastric mucosal thickness and cellular proliferation [26, 27]. The effect was thought to be mediated via muscarinic receptor type $3\left(M_{3} R\right)$ signaling, since knock-out of the $\mathrm{M}_{3} \mathrm{R}$ suppressed gastric cancer. These studies led to the conclusion that vagal innervation promotes gastric cancer via muscarinic M3 receptor in a Wnt mediated pathway [28]. However, in PCa, Renz et al. demonstrated that ablation of the vagal nerve actually accelerated cancer progression [3]. Treatment with the muscarinic receptor agonist, bethanechol was able to reverse the accelerated cancer progression due to vagal ablation. Overall, this study along with others led to the general hypothesis that vagal innervation has a cancerattenuating effect in the pancreas. In a wide-scale analysis of neural fiber quality in PCa specimens, we previously found a low parasympathetic fiber content of nerves that were invaded by pancreatic cancer cells [29]. In line with these previous studies, in the current study, we were able to demonstrate a cancer-cell-suppressive effect of AChE inhibition and thus indirect cholinergic activation in vitro and in vivo. However, this effect was obtained without directly interfering with the autonomous nervous system, and yet did also not translate into an improved clinical outcome, i.e. survival, in mouse $\mathrm{PCa}$. These findings are of major importance for all studies related the role of cholinergic / parasympathetic nervous system in cancer, since all components of the cholinergic system (ACh, acetylcholinesterase, muscarinic acetylcholine receptors, acetylcholine transferase) are not exclusively expressed by neurons but ubiquitously present in almost all mammalian cells, including non-neuronal cells [8].

In order to understand non-neuronal cholinergic signaling and its involvement in basic cellular functions, such as proliferation and differentiation [6], one has to consider the different subtypes of muscarinic receptors that initiate these diverse cellular outcomes. There are 5 different muscarinic receptor subtypes (M1R - M5R), all of which are $\mathrm{G}$ protein-coupled receptors but may lead to different intracellular cascades in order to exert different extracellular outcomes. Upon activation, oddnumbered muscarinic receptors couple to $G$ proteins that activate phospholipase $C-\beta$ to initiate the phosphatidylinositol trisphosphate cascade, whereas even numbered muscarinic receptors couple to $G$ proteins that inhibit adenylyl cyclase activity [9]. This complexity explains in part why, for instance, activation of the $M_{3} R$ subtype has been shown to promote cancer cell proliferation in gastric cancer, whereas activation of $M_{1} R$ subtype has been shown to attenuated pancreatic cancer proliferation. Although the role of muscarinic receptors in colon cancer has been previously characterized, most studies only focused on one of the 5 different receptors [9, 13]. Even though there has been extensive research about the tissue-specific expression of muscarinic receptors, a comprehensive overview about the role of muscarinic receptors and its ligands in different cancer entities is still missing.

The lack of basic research on non-neuronal cholinergic signaling is even more evident for PCa. Very little is known about the role of the different muscarinic receptor subtypes as well as other components of the cholinergic-signaling-machinery, such as ChAT, AChE or ACh expression in PCa.

Therefore, our study contributes to the attempts to understand the non-neuronal AChE in PCa. Here, we demonstrated mild to weak staining in premalignant lesions, with increasing staining in overt pancreatic cancer. Mammals express 3 different classes of AChE, which differ with regard to their subunits. Each type of AChE has a different 3' RNA sequence with a corresponding Cterminal sequence, which encodes the respective subunit. The $\mathrm{AChE}_{\mathrm{H}}$ subunit contains a hydrophobic Cterminal sequence forming amphilic monomers and dimers and incorporates a GPI [6]. It is therefore often found closely spaced to the cell membrane. This would explain the perimembranous staining found in our study.

Based on our findings, indirect activation of cholinergic signaling via $\mathrm{AChE}$ inhibition is not sufficient to achieve a survival benefit in $\mathrm{PCa}$, although it resulted in a prominent suppression of the tumor-associated inflammation in the tumor, and a drop of serum cytokine levels. This conclusion, which is based on our findings from a translational mouse PCa model and from human $\mathrm{PCa}$, underlines that increasing the cholinergic input for attenuating $\mathrm{PCa}$ progression and for improving patient survival will probably not be possible via administration of two widely used clinical drugs, i.e. physostigmine and pyridostigmine. In contrast, Renz et al. made use of a direct activator of muscarinic cholinergic signaling. i.e. the bethanechol, which did result in improved survival in the KPC model of PCa [3]. In the present study, we combined the indirect cholinergics with an older chemotherapeutic, i.e. gemcitabine, in the adjuvant and palliative treatment. It is imaginable that a combination with a more current regimen such as gemcitabine and nabpaclitaxel or with FOLFIRINOX may yield even more potent results. Nonetheless, we observed immunosuppressive effects of indirect cholinergic stimulation in our study. It is conceivable that in a more humanized model, this immunmodulatory effect of indirect cholinergic stimulation may have been much greater. The NMRI- 
Foxn $1^{\text {nu/nu }}$ model is deficient with regard to $\mathrm{T}$ cell function due to a thymus abnormality. For this reason, we primarily assessed macrophage distribution upon treatment with indirect cholinergic agents. As a recent report showed, cholinergic activity of the vagus nerve inhibits macrophage-derived tumor necrosis factor- $\alpha$ secretion via $\mathrm{T}$-cell derived acetylcholine in the spleen [30]. Our data suggest that there may also be a T-cellindependent, immunosuppressive effect of cholinergic activation on macrophages.

\section{Conclusion}

The present study suggests that the growth-suppressive effects of inhibition of the non-neuronal, cancer-cellintrinsic $\mathrm{AChE}$ via indirect parasympahomimetic drugs do not translate into improved survival in PCa. Therefore, targeting $\mathrm{PCa}$ over its nervous-cholinergic side should pursue the track of direct, rather than indirect, parasympathetic-cholinergic activation. Future clinical study designs should thus include novel, selective direct muscarinic agonists, rather than clinically available, widely used indirect agonists.

\section{Supplementary Information}

The online version contains supplementary material available at https://doi. org/10.1186/s13046-020-01796-4.

\section{Additional file 1.}

\section{Abbreviations}

ACh: Acetylcholine; AChE: Acetylcholine esterase; ChAT: Choline acetyltransferase; ERK: Extracellular signal-regulated kinase; MAPK: Mitogenactivated protein kinase; $M_{1} R$ : Muscarinic receptor type; $M_{3} R$ : Muscarinic receptor type; PCa: Pancreatic cancer; PCC: Pancreatic cancer cells

\section{Acknowledgements}

This work is part of PLP'S MD thesis.

\section{Financial disclosures}

None.

\section{Authors' contributions}

IED and GOC designed the study. PLP, KW, ED, EG, BFM, JB, LR, JGD, MJ, and ST performed the experiments. PLP, ST, CJ and IED analyzed the data. AH, RI and FK contributed substantial intellectual input and new experimental models. HF supervised the study. PLP, LF and IED wrote the first draft of the manuscript. All authors have agreed on the final version of the manuscript.

\section{Funding}

No specific funding to be declared. Open Access funding enabled and organized by Projekt DEAL.

\section{Availability of data and materials}

All data are available from the Authors upon reasonable request.

\section{Ethics approval and consent to participate}

All animal studies were conducted according to the national regulations and approved by the Regierung von Oberbayern (approval nr. ROB-55.22532.Vet_02-16-165 and 55.2-1-54-2531-36-08), and Hannover (15/1949). The study has been approved by the ethics committee of the Technische Universität München, Munich (approval nr. 154/20). All patients were informed, and written consent was obtained for tissue collection.

\section{Consent for publication}

Was obtained from all authors.

\section{Competing interests}

None.

\section{Author details}

${ }^{1}$ Department of Surgery, Klinikum rechts der Isar, Technical University of Munich, School of Medicine, Ismaninger Str. 22, 81675 Munich, Germany. ${ }^{2}$ Key laboratory of Carcinogenesis and Translational Research (Ministry of Education), Department of Hepatic, Biliary \& Pancreatic Surgery, Peking University School of Oncology, Beijing Cancer Hospital \& Institute, Beijing 100710, China. ${ }^{3}$ Department of Gastroenterology, Hepatology, and Endocrinology, Hannover Medical School, Hannover, Germany. ${ }^{4}$ Department of General, Visceral, and Transplantation Surgery,

Ludwig-Maximilians-University Munich, Munich, Germany. ${ }^{5}$ Department of General and Thoracic Surgery, University Hospital of Giessen, Giessen, Germany. ${ }^{6}$ Institute of Pathology, Klinikum rechts der Isar, Technical University of Munich, School of Medicine, Munich, Germany. 'Department of General Surgery (Gastrointestinal Surgery), The Affiliated Hospital of Southwest Medical University, Luzhou, Sichuan, China. ${ }^{8}$ German Cancer Consortium (DKTK), Partner Site Munich, Munich, Germany. ${ }^{9}$ CRC 1321 Modelling and Targeting Pancreatic Cancer, Munich, Germany. ${ }^{10}$ Department of General Surgery, HPB-Unit, School of Medicine, Acibadem Mehmet Ali Aydinlar University, Istanbul, Turkey.

Received: 17 August 2020 Accepted: 2 December 2020

Published online: 24 December 2020

\section{References}

1. Zahalka AH, Frenette PS. Nerves in cancer. Nat Rev Cancer. 2020;20(3):14357. https://doi.org/10.1038/s41568-019-0237-2.

2. Partecke LI, Kading A, Trung DN, Diedrich S, Sendler M, Weiss F, Kuhn JP, Mayerle J, Beyer K, von Bernstorff W, Heidecke CD, Kessler W. Subdiaphragmatic vagotomy promotes tumor growth and reduces survival via TNFalpha in a murine pancreatic cancer model. Oncotarget. 2017;8(14): 22501-12. https://doi.org/10.18632/oncotarget.15019.

3. Renz BW, Tanaka T, Sunagawa M, Takahashi R, Jiang Z, Macchini M, Dantes Z, Valenti G, White RA, Middelhoff MA, IImer M, Oberstein PE, Angele MK, Deng $\mathrm{H}$, Hayakawa $Y$, Westphalen CB, Werner J, Remotti H, Reichert M, Tailor YH, Nagar K, Friedman RA, luga AC, Olive KP, Wang TC. Cholinergic signaling via muscarinic receptors directly and indirectly suppresses pancreatic tumorigenesis and cancer Stemness. Cancer Discov. 2018;8(11): 1458-73. https://doi.org/10.1158/2159-8290.CD-18-0046.

4. Soreq $\mathrm{H}$, Lapidot-Lifson $\mathrm{Y}, \mathrm{Z}$ akut $\mathrm{H}$. A role for cholinesterases in tumorigenesis? Cancer Cells. 1991;3(12):511-6.

5. Wessler I, Kirkpatrick CJ. Acetylcholine beyond neurons: the non-neuronal cholinergic system in humans. Br J Pharmacol. 2008;154(8):1558-71. https:// doi.org/10.1038/bjp.2008.185.

6. Campoy FJ, Vidal CJ, Munoz-Delgado E, Montenegro MF, Cabezas-Herrera J, Nieto-Ceron S. Cholinergic system and cell proliferation. Chem Biol Interact. 2016;259(Pt B):257-65. https://doi.org/10.1016/j.cbi.2016.04.014.

7. Eglen RM. Muscarinic receptor subtypes in neuronal and non-neuronal cholinergic function. Auton Autacoid Pharmacol. 2006;26(3):219-33. https:// doi.org/10.1111/j.1474-8673.2006.00368.x.

8. Wessler I, Kirkpatrick CJ, Racke K. The cholinergic 'pitfall': acetylcholine, a universal cell molecule in biological systems, including humans. Clin Exp Pharmacol Physiol. 1999;26(3):198-205. https://doi.org/10.1046/j.1440-1681. 1999.03016.x.

9. Shah N, Khurana S, Cheng K, Raufman JP. Muscarinic receptors and ligands in cancer. Am J Physiol Cell Physiol. 2009;296(2):C221-32. https://doi.org/10. 1152/ajpcell.00514.2008.

10. Cheng K, Samimi R, Xie G, Shant J, Drachenberg C, Wade M, Davis RJ, Nomikos G, Raufman JP. Acetylcholine release by human colon cancer cells mediates autocrine stimulation of cell proliferation. Am J Physiol Gastrointest Liver Physiol. 2008;295(3):G591-7.

11. Zhao Y, Wang X, Wang T, Hu X, Hui X, Yan M, Gao Q, Chen T, Li J, Yao M, Wan D, Gu J, Fan J, He X. Acetylcholinesterase, a key prognostic predictor for hepatocellular carcinoma, suppresses cell growth and induces chemosensitization. Hepatology. 2011;53(2):493-503. https://doi.org/10. 1002/hep.24079. 
12. Lee CH, Huang CS, Chen CS, Tu SH, Wang YJ, Chang YJ, Tam KW, Wei PL, Cheng TC, Chu JS, Chen LC, Wu CH, Ho YS. Overexpression and activation of the alpha9-nicotinic receptor during tumorigenesis in human breast epithelial cells. J Natl Cancer Inst. 2010;102(17):1322-35. https://doi.org/10. 1093/jnci/djq300.

13. Raufman JP, Samimi R, Shah N, Khurana S, Shant J, Drachenberg C, Xie G, Wess J, Cheng K. Genetic ablation of M3 muscarinic receptors attenuates murine colon epithelial cell proliferation and neoplasia. Cancer Res. 2008; 68(10):3573-8. https://doi.org/10.1158/0008-5472.CAN-07-6810.

14. Phillips PA, Yang L, Shulkes A, Vonlaufen A, Poljak A, Bustamante S, Warren A, Xu Z, Guilhaus M, Pirola R, Apte MV, Wilson JS. Pancreatic stellate cells produce acetylcholine and may play a role in pancreatic exocrine secretion. Proc Natl Acad Sci U S A. 2010;107(40):17397-402.

15. Gurlevik E, Fleischmann-Mundt B, Brooks J, Demir IE, Steiger K, Ribback S, Yevsa T, Woller N, Kloos A, Ostroumov D, Armbrecht N, Manns MP, Dombrowski F, Saborowski M, Kleine M, Wirth TC, Oettle H, Ceyhan GO, Esposito I, Calvisi DF, Kubicka S, Kuhnel F. Administration of gemcitabine after pancreatic tumor resection in mice induces an antitumor immune response mediated by natural killer cells. Gastroenterology. 2016;151(2):338350 e337.

16. Hingorani SR, Petricoin EF, Maitra A, Rajapakse V, King C, Jacobetz MA, Ross S, Conrads TP, Veenstra TD, Hitt BA, Kawaguchi Y, Johann D, Liotta LA, Crawford HC, Putt ME, Jacks T, Wright CV, Hruban RH, Lowy AM, Tuveson DA. Preinvasive and invasive ductal pancreatic cancer and its early detection in the mouse. Cancer Cell. 2003;4(6):437-50.

17. Hingorani SR, Wang L, Multani AS, Combs C, Deramaudt TB, Hruban RH, Rustgi AK, Chang S, Tuveson DA. Trp53R172H and KrasG12D cooperate to promote chromosomal instability and widely metastatic pancreatic ductal adenocarcinoma in mice. Cancer Cell. 2005;7(5):469-83.

18. Ceyhan GO, Bergmann F, Kadihasanoglu M, Altintas B, Demir IE, Hinz U, Muller MW, Giese T, Buchler MW, Giese NA, Friess H. Pancreatic neuropathy and neuropathic pain--a comprehensive pathomorphological study of 546 cases. Gastroenterology. 2009;136(1):177-186 e171. https://doi.org/10.1053/j. gastro.2008.09.029.

19. Lu L, Zhang X, Zhang B, Wu J, Zhang X. Synaptic acetylcholinesterase targeted by microRNA-212 functions as a tumor suppressor in non-smal cell lung cancer. Int J Biochem Cell Biol. 2013;45(11):2530-40. https://doi. org/10.1016/j.biocel.2013.08.007.

20. Bigbee JW, Sharma KV. The adhesive role of acetylcholinesterase (AChE): detection of AChE binding proteins in developing rat spinal cord. Neurochem Res. 2004;29(11):2043-50. https://doi.org/10.1007/s1 1064-0046877-x.

21. Fujii T, Mashimo M, Moriwaki Y, Misawa H, Ono S, Horiguchi K, Kawashima K. Expression and function of the cholinergic system in immune cells. Front Immunol. 2017;8:1085. https://doi.org/10.3389/fimmu.2017.01085.

22. Habtezion A, Edderkaoui M, Pandol SJ. Macrophages and pancreatic ductal adenocarcinoma. Cancer Lett. 2016;381(1):211-6. https://doi.org/10.1016/j. canlet.2015.11.049

23. McCubrey JA, Steelman LS, Chappell WH, Abrams SL, Wong EW, Chang F, Lehmann B, Terrian DM, Milella M, Tafuri A, Stivala F, Libra M, Basecke J, Evangelisti C, Martelli AM, Franklin RA. Roles of the Raf/MEK/ERK pathway in cell growth, malignant transformation and drug resistance. Biochim Biophys Acta. 2007;1773(8):1263-84. https://doi.org/10.1016/j.bbamcr.2006.10.001

24. Huang XY, Wang HC, Yuan Z, Huang J, Zheng Q. Norepinephrine stimulates pancreatic cancer cell proliferation, migration and invasion via betaadrenergic receptor-dependent activation of P38/MAPK pathway. Hepatogastroenterology. 2012;59(115):889-93. https://doi.org/10.5754/ hge11476.

25. Valladares A, Alvarez AM, Ventura JJ, Roncero C, Benito M, Porras A. p38 mitogen-activated protein kinase mediates tumor necrosis factor-alphainduced apoptosis in rat fetal brown adipocytes. Endocrinology. 2000; 141(12):4383-95. https://doi.org/10.1210/endo.141.12.7843.

26. Hakanson R, Vallgren S, Ekelund M, Rehfeld JF, Sundler F. The vagus exerts trophic control of the stomach in the rat. Gastroenterology. 1984;86(1):2832.

27. Axelson J, Ekelund M, Hakanson R, Sundler F. Gastrin and the vagus interact in the trophic control of the rat oxyntic mucosa. Regul Pept. 1988;22(3):23743.

28. Zhao CM, Hayakawa Y, Kodama Y, Muthupalani S, Westphalen CB, Andersen GT, Flatberg A, Johannessen H, Friedman RA, Renz BW, Sandvik AK, Beisvag V, Tomita H, Hara A, Quante M, Li Z, Gershon MD, Kaneko K, Fox JG, Wang
TC, Chen D. Denervation suppresses gastric tumorigenesis. Sci Transl Med. 2014;6(250):250ra115. https://doi.org/10.1126/scitransImed.3009569.

29. Ceyhan GO, Demir IE, Rauch U, Bergmann F, Muller MW, Buchler MW, Friess $\mathrm{H}$, Schafer KH. Pancreatic neuropathy results in "neural remodeling" and altered pancreatic innervation in chronic pancreatitis and pancreatic cancer. Am J Gastroenterol. 2009;104(10):2555-65. https://doi.org/10.1038/ajg.2009. 380.

30. Rosas-Ballina M, Olofsson PS, Ochani M, Valdes-Ferrer SI, Levine YA, Reardon C, Tusche MW, Pavlov VA, Andersson U, Chavan S, Mak TW, Tracey KJ. Acetylcholine-synthesizing $T$ cells relay neural signals in a vagus nerve circuit. Science. 2011;334(6052):98-101. https://doi.org/10.1126/science. 1209985.

\section{Publisher's Note}

Springer Nature remains neutral with regard to jurisdictional claims in published maps and institutional affiliations.

\section{Ready to submit your research? Choose BMC and benefit from:}

- fast, convenient online submission

- thorough peer review by experienced researchers in your field

- rapid publication on acceptance

- support for research data, including large and complex data types

- gold Open Access which fosters wider collaboration and increased citations

- maximum visibility for your research: over $100 \mathrm{M}$ website views per year

At BMC, research is always in progress.

Learn more biomedcentral.com/submissions 